\title{
Persistent Changes in Spontaneous Firing of Purkinje Neurons Triggered by the Nitric Oxide Signaling Cascade
}

\author{
Spencer L. Smith and Thomas S. Otis \\ Department of Neurobiology and Brain Research Institute, University of California at Los Angeles School of Medicine, Los Angeles, California 90095
}

\begin{abstract}
Many types of neurons fire spontaneously because of the activity of pacemaking ion channels. Although endogenous firing can serve as a persistent signal to downstream targets, little attention has been paid to factors that might modulate such intrinsic electrical activity. We tested for modulation of spontaneous firing of Purkinje neurons in cerebellar slices under conditions in which principal synaptic inputs were blocked. Loose-patch recordings from single neurons show that sustained ( $>40 \mathrm{~min}$ ) increases in the spontaneous firing rate can be triggered by activation of the nitric oxide-cGMP signaling pathway. Inhibitors of soluble guanylate cyclase and protein kinase $\mathrm{G}$ block this modulation. Increases in firing rate are also observed after stimulation of parallel fibers but not in response to basket cell activity. These findings elucidate a novel role for the nitric oxide-cGMP signaling cascade in the brain. This mechanism could permit long-term adjustments in the baseline firing rate of endogenously active neurons in response to changes in afferent activity.
\end{abstract}

Key words: intrinsic; protein kinase G; cGMP; cerebellum; nitric oxide synthase; pacemaking

\section{Introduction}

Spontaneously firing neurons are found in several regions of the brain, including the midbrain, the hypothalamus, the basal ganglia, and the cerebellum (Llinas and Sugimori, 1980; du Lac and Lisberger, 1995; Uteshev et al., 1995; Häusser and Clark, 1997; Bevan and Wilson, 1999; Ghamari-Langroudi and Bourque, 2000). Synaptic input is not necessary to generate spontaneous firing. Rather, in many of these cell types, intrinsic electrical activity generates rapid and extremely regular spiking rates. Specific pacemaking ion channels, such as $I_{\mathrm{h}}$, mixed cation currents, or TTX-sensitive $\mathrm{Na}^{+}$currents, are implicated in this endogenous activity (Uteshev et al., 1995; Bevan and Wilson, 1999; Raman and Bean, 1999; Ghamari-Langroudi and Bourque, 2000; Raman et al., 2000). Although intrinsically generated spiking activity represents a persistent signal to downstream targets, little is known about how a given neuron determines and regulates its characteristic firing rate.

Cerebellar Purkinje neurons fire with remarkable regularity at high rates even in the absence of excitatory synaptic inputs (Häusser and Clark, 1997; Raman and Bean, 1999). Both in vitro and in vivo, an individual Purkinje neuron maintains a distinct resting firing rate (Armstrong and Rawson, 1979; Häusser and Clark, 1997; Raman and Bean, 1997). A survey across many Purkinje neurons shows that some cells fire as slowly as 5 spikes/sec, whereas others fire as rapidly as $80 \mathrm{spikes} / \mathrm{sec}$. The factors that determine resting firing rates are not understood, nor is it known

Received Sept. 16, 2002; revised 0ct. 17, 2002; accepted 0ct. 22, 2002.

This project was supported by a grant from the Whitehall Foundation (T.S.O.) and National Science Foundation Training Grant DGE-997802 (S.L.S.). We are grateful to G. Brasnjo, J. Dzubay, J. Feldman, L. Ignarro, P. Meera, and F. Schweizer for comments on this manuscript and A. Jacobs for assistance with the nitric oxide measurements.

Correspondence should be addressed to Thomas S. Otis, Department of Neurobiology and Brain Research Institute, University of California at Los Angeles School of Medicine, 650 Charles Young Drive South, Los Angeles, CA 90095. E-mail: otist@ucla.edu.

Copyright $\odot 2003$ Society for Neuroscience $\quad 0270-6474 / 03 / 220367-06 \$ 15.00 / 0$ whether individual cells can make long-term adjustments in their firing rates.

In the cerebellar cortex, elements of the nitric oxide (NO) signaling cascade are expressed at some of the highest levels in the brain. Granule and basket cells express the neuronal form of nitric oxide synthase (NOS) (Bredt et al., 1990), whereas Purkinje neurons express soluble guanylyl cyclase (sGC) (Ariano et al., 1982) and cGMP-regulated protein kinase (PKG) (Lohmann et al., 1981). In addition, G substrate, a proposed substrate of $P K G$, is found only in Purkinje neurons (Schlichter et al., 1978, 1980). Despite the prominence of this signaling cascade in cerebellum, its role is controversial.

We show in the present study that, independent of fast synaptic transmission, cGMP analogs and NO donors cause a longterm increase in the spontaneous firing rate of Purkinje neurons. Furthermore, the NO-induced increase is blocked by inhibitors of sGC and PKG. We also show evidence that $\mathrm{NO}$ generated by parallel fiber activity can cause similar effects. These results highlight an alternative mechanism for circuit plasticity in which nitric oxide signals to groups of spontaneously active neurons to adjust their baseline firing rates.

\section{Materials and Methods}

Standard techniques were used to prepare $300-\mu \mathrm{m}$-thick parasagittal cerebellar slices (Brasnjo and Otis, 2001). With the aid of an upright microscope, loose-patch (15-200 M $\Omega$ seal resistance) extracellular recordings were made from the soma of visually identified Purkinje neurons in slices from 15- to 22-d-old rats. Glass pipettes (impedance, 1-3 $\mathrm{M} \Omega$ ) were filled with $119 \mathrm{~mm} \mathrm{NaCl}$ and buffered with $10 \mathrm{~mm}$ HEPES. A fraction of the cells $(\sim 10 \%)$ did not show persistent firing (defined by pauses lasting $>1 \mathrm{sec}$ ) during the 10 min control period; if this occurred, the experiment was terminated. Extracellular solutions contained the following (in mM): $119 \mathrm{NaCl}, 26 \mathrm{NaHCO}_{3}, 11$ glucose, $2.5 \mathrm{KCl}, 2.5 \mathrm{CaCl}_{2}$, $1.3 \mathrm{MgCl}_{2}, 1 \mathrm{NaH}_{2} \mathrm{PO}_{4}, 0.1$ picrotoxin, and either $10 \mu \mathrm{M} 6,7-$ dinitroquinoxaline-2,3-dione (DNQX) or $5 \mathrm{~mm}$ kynurenic acid to block 
AMPA receptors. In some experiments, $100 \mu \mathrm{M}$ D,L-APV was added; no differences were noted, and the data were pooled. Solutions were saturated with $95 \% \mathrm{O}_{2}-5 \% \mathrm{CO}_{2}$ and maintained at $30-33^{\circ} \mathrm{C}$ throughout the experiments. Pilot experiments showed no difference between preapplication and coapplication of the drugs used. For parallel fiber stimulation, previously published stimulus parameters were used (Shibuki and Kimura, 1997). A bipolar metal electrode was placed between 150 and $250 \mu \mathrm{m}$ from the Purkinje cell body. Stimuli consisted of bipolar pulses (175-675 $\mu \mathrm{A} / 100 \mu \mathrm{sec}$, each phase). Whole-cell current-clamp recordings of basket cells were made using 3-6 $\mathrm{M} \Omega$ pipettes filled with the following (in mM): $122 \mathrm{~K}$-methane sulfonate, $5 \mathrm{KCl}, 1 \mathrm{NaCl}, 2 \mathrm{MgCl}_{2}, 10$ HEPES, 2 ATP, and 0.4 GTP. Signals were recorded using Axopatch 200B or $2 \mathrm{~B}$ amplifiers (Axon Instruments, Foster City, $\mathrm{CA}$ ) and Dagan (Minneapolis, MN) BVC-700A amplifiers. Igor programs (Wavemetrics, Lake Oswego, OR) implementing a simple threshold-crossing algorithm were used to detect single-unit activity; the large signal-to-noise ratio in the recordings permitted unambiguous spike detection. In the parallel fiber (PF) stimulation experiment, cells that exhibited $>30 \%$ changes in firing rate within 2 min of stimulus onset $(n=3)$ were excluded. Data are shown as an average \pm SEM unless otherwise noted. NO release by the nitric oxide donor NOR-4 was measured using an electrochemical nitric oxide probe (World Precision Instruments, Sarasota, FL). Temperature and test solution were identical to those used in the experiments.

\section{Results}

To monitor intrinsically generated spontaneous firing, loosepatch extracellular recordings were made from single Purkinje neurons in cerebellar slices continuously bathed in antagonists of $\mathrm{GABA}_{\mathrm{A}}$, AMPA, kainate, and (in some cases) NMDA receptors. As reported previously (Häusser and Clark, 1997), Purkinje neurons fire regularly when $\mathrm{GABA}_{\mathrm{A}}$ receptors are blocked. Confirming this result, histograms of interspike intervals were well fit by Gaussian functions (Fig. 1B) and showed small coefficients of variation $(\mathrm{CVs})$. The average $\mathrm{CV}$ measured in a $5 \mathrm{~min}$ period for 20 neurons was $3.0 \pm 2.7 \%$. Moreover, this regular firing pattern was maintained over time in control recordings; comparisons of mean firing rates for 10 min periods separated by $30 \mathrm{~min}$ showed no significant change in firing rate $(105.3 \pm 3.6 \%$ of control rate; $n=4 ; p=0.91)$.

An NO donor causes an increase in spontaneous firing rate Exposure of slices for $10 \mathrm{~min}$ to the nitric oxide donor NOR-4 $(100 \mu \mathrm{M})$ resulted in a slow increase in spontaneous firing rate that was maintained after removal of the NO donor from the perfusion chamber (Fig. 1). The average increase was to $111.4 \pm$ $1.8 \%$ ( 7 min after NO; $n=6 ; p=0.0015$ ) of control, and the relative increase was similar over a wide range of control firing rates $(3-50 \mathrm{~Hz})$ (see Fig. 3). Firing rates remained elevated for $\geq 50 \mathrm{~min}$ after washout of the NO donor $(116.8 \pm 4.9 \%, 50 \mathrm{~min}$ after NO; $n=6 ; p=0.019$ ).

Separate in vitro calibration experiments (see Materials and Methods) indicated that the steady-state concentration of NO achieved under these conditions was $\sim 35 \mathrm{nM}$. This is five to seven times the NO concentration generated by release from parallel fibers in cerebellar slices as measured by electrochemical methods (Shibuki and Kimura, 1997; Kimura et al., 1998).

cGMP analogs cause an increase in spontaneous firing rate sGC, the enzyme that synthesizes cGMP and an NO target, is present at high levels in Purkinje neurons; therefore, we tested whether membrane-permeable forms of cGMP increased firing rate. Application of the membrane-permeable cGMP analogs 8pCPT-cGMP $(50 \mu \mathrm{M})$ or $8-B r-c G M P(50 \mu \mathrm{M})$ for $10 \mathrm{~min}$ mimicked the effects of NO donors [8p-CPT-cGMP, $117.7 \pm 4.1 \% 7$ min after NO, $n=10, p=0.0019$ (Fig. $2 B$ ); 8-Br-cGMP, $118.0 \pm$
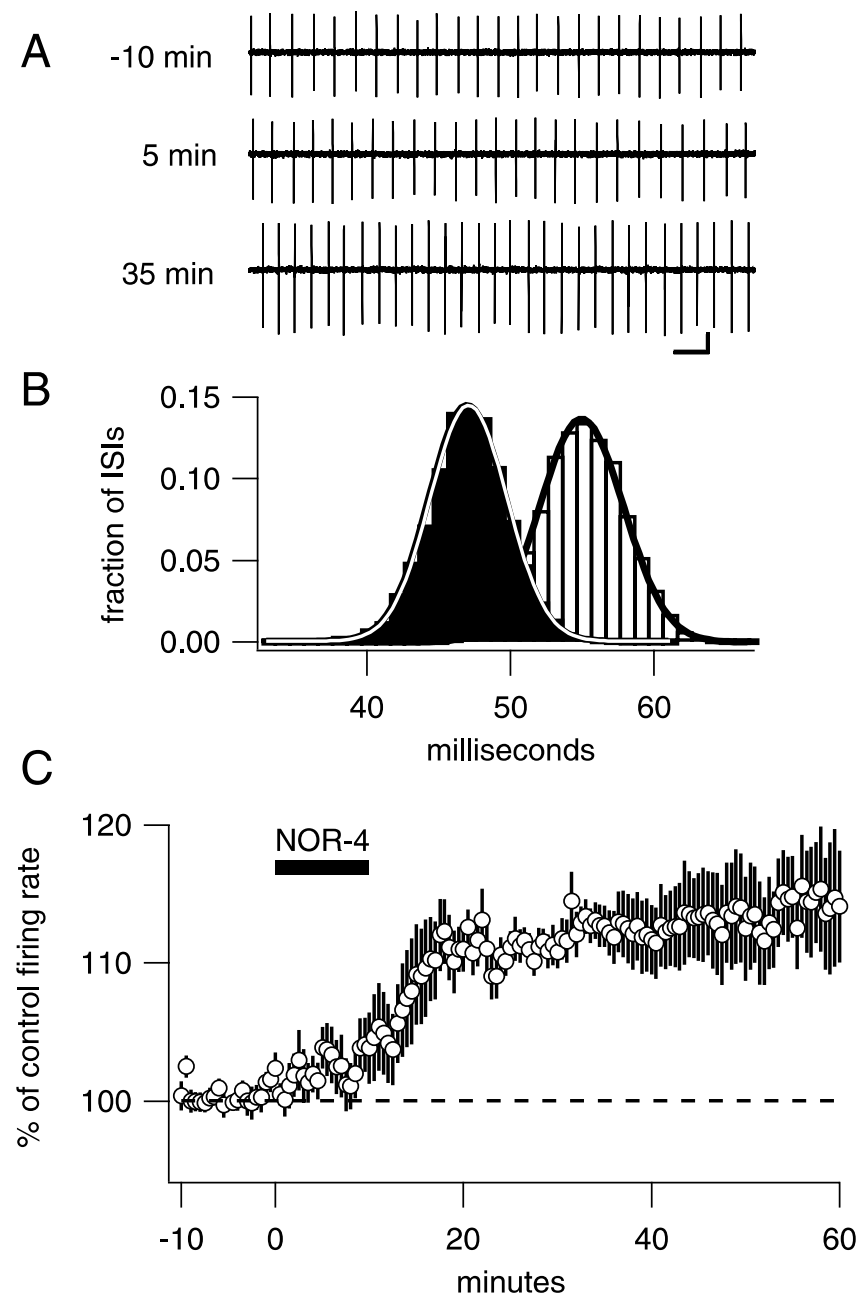

Figure 1. The nitric oxide donor NOR-4 causes an increase in baseline firing rate. $A$, Example traces taken at times $-10 \mathrm{~min}, 5 \mathrm{~min}$, and 35 min relative to the start of NOR-4 application ( $C$ ). Calibration: 75 pA, $100 \mathrm{msec}$. B, Histograms of interspike intervals (IS/s) constructed from 10 min periods at $-10 \mathrm{~min}$ (open bars) and $30 \mathrm{~min}$ ( filled bars). Superimposed are Gaussian curves of the form

$$
y=A e^{-\frac{(x-\bar{x})^{2}}{2 S D^{2}}}
$$

where $A$ is an amplitude factor, and $\bar{x}$ is the mean. For the open bars, $\bar{x}=55 \mathrm{msec}, \mathrm{SD}=2.9$, and $A=0.137$; for the filled bars, $\bar{x}=47 \mathrm{msec}, \mathrm{SD}=2.7$, and $A=0.145 . \chi^{2}$ values for both fits are $<2 \times 10^{-4}$. C, Normalized, average firing rate versus time for six neurons. After a $10 \mathrm{~min}$ control period, $100 \mu \mathrm{m}$ NOR-4 was added to the bath as indicated by the bar. On average, firing rates increased $11.4 \pm 1.8 \%$ (at $t=17 \mathrm{~min}$ ) and remained elevated for $>50 \mathrm{~min}$.

$3.1 \%, n=4, p=0.0097]$. Similar to NO donors, these increases were long lasting (126.8 $\pm 8.7 \% 30 \mathrm{~min}$ after $8 \mathrm{p}-\mathrm{CPT}-\mathrm{GMP} ; n=$ $10 ; p=0.013$ ) (Fig. $2 B$ ). As a result of cGMP analog-induced increases in spiking rate, some cells began firing so rapidly that they exhibited a repeating pattern in which the firing rate ramped up to $>80 \mathrm{~Hz}$, stopped entirely for several seconds (presumably because of depolarization block), resumed firing at a rate elevated from the control rate, and ramped up until another pause was induced. Such cells were included in the average of cGMP-treated cells in Figure $2 B$ and account for the increase in the variability after drug application. Note also that this hyperexcited firing pattern leads to underestimation of peak firing rates in Figure $2 \mathrm{~B}$. To test the idea further that NO activates sGC to increase firing rate, we tested the effects of oxadiazolo quinoxalin-1-one (ODQ), a specific inhibitor of sGC. ODQ alone caused no signif- 
A
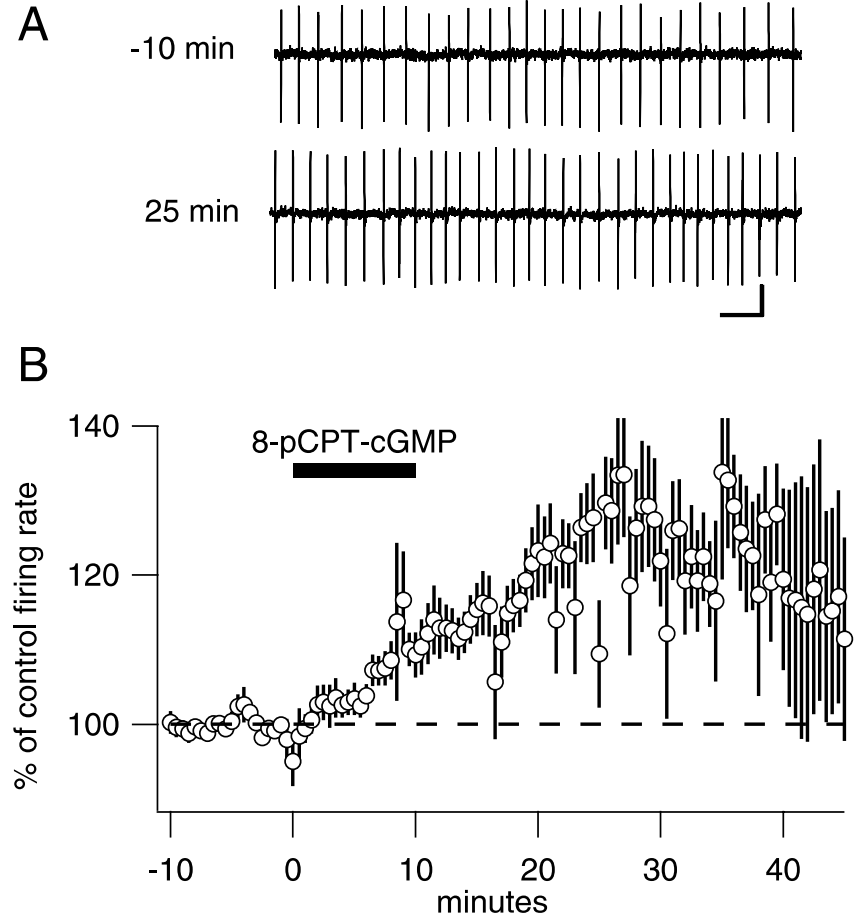

Figure 2. Membrane-permeant CGMP analogs also increase baseline firing rate. $A$, Example traces from one neuron in control and $35 \mathrm{~min}$ after application of $50 \mu \mathrm{m} 8 \mathrm{p}$-CPT-CGMP. Calibration: $30 \mathrm{pA}, 100 \mathrm{msec} . B$, Average, normalized firing rate versus time for 10 Purkinje neurons. After a $10 \mathrm{~min}$ control period, $50 \mu \mathrm{m} 8 \mathrm{p}$-CPT-CGMP was added at the indicated time. $0 \mathrm{n}$ average, the firing rate increased $17.7 \pm 4.1 \%$.

icant change in firing rate $(n=4)$. Coapplication of ODQ with NOR-4 blocked the increase in firing rate (Fig. $3 C$ ), confirming that sGC activity is required for modulation.

PKG is necessary for NO-induced increase in firing rate A rise in cytoplasmic cGMP concentration in Purkinje cells could increase endogenous firing through at least two types of mechanisms. Cyclic nucleotide-gated (CNG) cation channels could increase spiking by depolarizing the membrane potential. Alternatively, cGMP could activate PKG, a protein kinase expressed at high levels by Purkinje neurons (Lohmann et al., 1981). PKG could then either directly phosphorylate ion channels involved in pacemaking or phosphorylate channel-associated proteins and thereby increase the excitability of the cell. Coapplication of a specific inhibitor of PKG type I activity (KT5823, $1 \mu \mathrm{M}$ ) with NOR-4 blocked the increase in firing rate (Fig. $3 C$ ), indicating that PKG is a necessary downstream effector of nitric oxide. The involvement of a protein kinase may explain the relatively slow onset of increased firing. It also raises the possibility that PKG substrates, possibly ion channels involved in pacemaking or related proteins, are involved in triggering sustained increases in spontaneous firing.

Testing for endogenous activity-dependent production of NO Because NOS is expressed by both granule neurons and basket cells, we tested whether activity in these neurons was able to generate NOS-dependent increases in firing rate. To stimulate PFs, the axons of granule neurons, we used previously published stimulation parameters to ensure that substantial NO release occurred (Shibuki and Kimura, 1997; Kimura et al., 1998). These experiments were performed in the presence of $100 \mu \mathrm{M}$
A

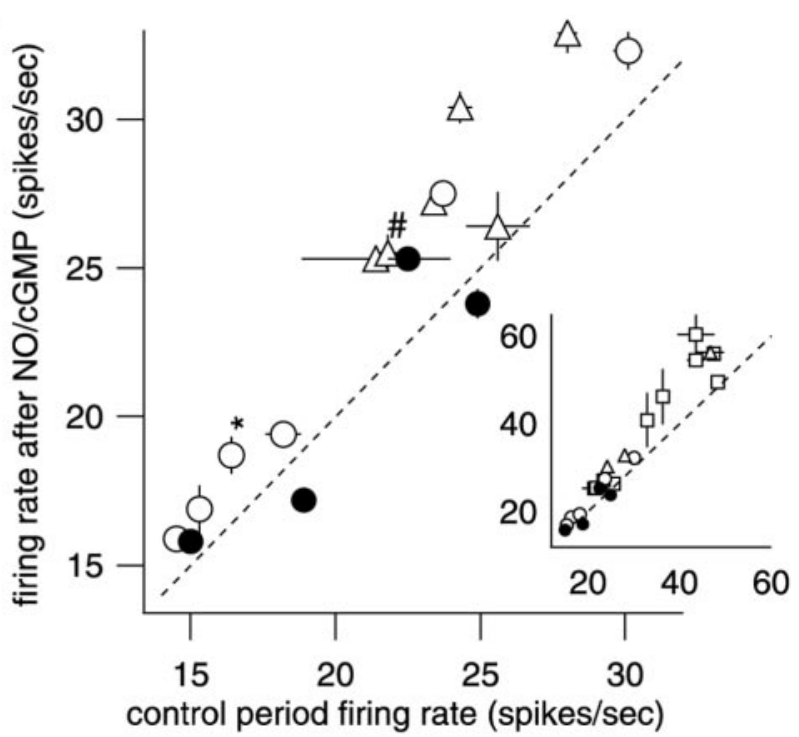

B
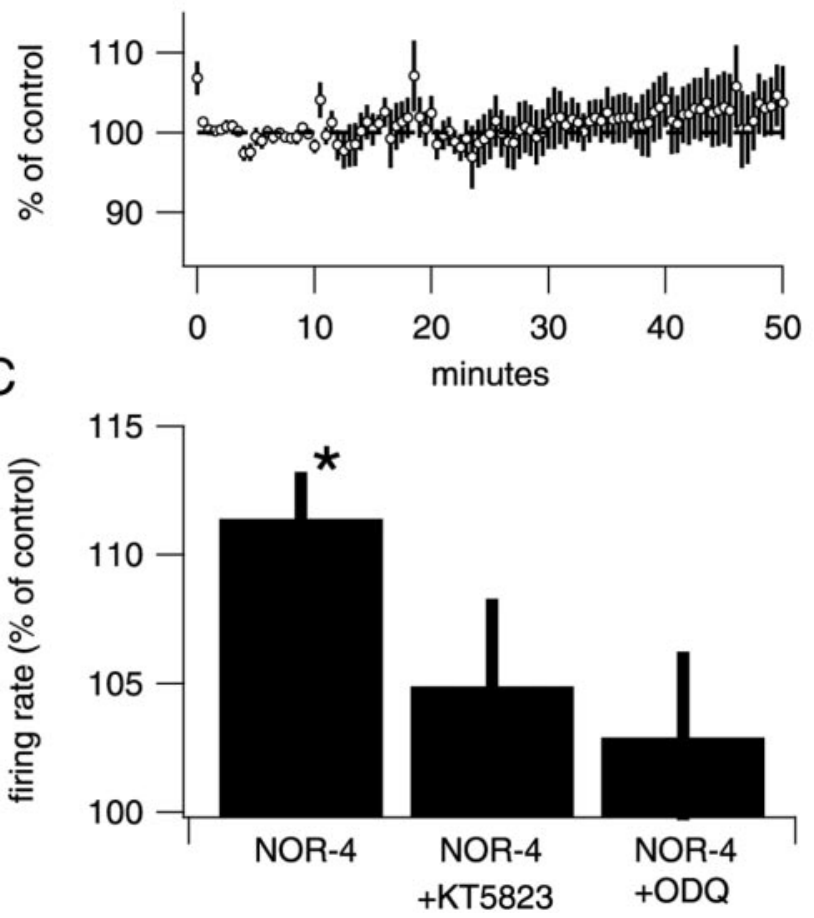

Figure 3. Summary data for $8 p-C P T-c G M P, N O R-4$, and control cells. A, Plot of the control firing rate for each cell measured over the 5 min period just before drug application versus the firing rate $7 \mathrm{~min}$ after the end of the experimental treatment. Each type of experiment is represented by different symbols (control, $\bigcirc$; NOR-4, $\bigcirc ; 8$ p-CPT-cGMP, $\square$; 8 -Br-cGMP, $\triangle$ ), and the error bars indicate SD. The diagonal dotted line indicates no change in firing rate. The vertical distance between the marker and the dotted line represents the number of additional spikes every second. ${ }^{*}$ denotes the example cell in Figure 1 , and \# indicates the example cell in Figure 2. Inset, Shown at a compressed scale to show the cells with higher firing rates. $B$, Average time course of four control cells. Although there is a small tendency toward increased firing rates, it is not significant and does not resemble the increases seen in the experimental conditions. C, Histogram shows average change in firing rate at $t=5-10 \mathrm{~min}$ after drug application compared with control $(-5-0 \mathrm{~min})$ under various conditions. NOR-4 increased firing rate $(n=6 ; p=0.0015)$. $\mathrm{ODQ}(10 \mu \mathrm{M})$, an inhibitor of $\mathrm{sGC}$ activity, blocked the increase in firing rate when coapplied with NOR-4 $(n=4 ; p=0.24)$. KT5823 $(1 \mu \mathrm{M})$, an inhibitor of PKG activity, also blocked an increase in firing rate when coapplied with NOR $(n=6 ; p=0.87)$. 

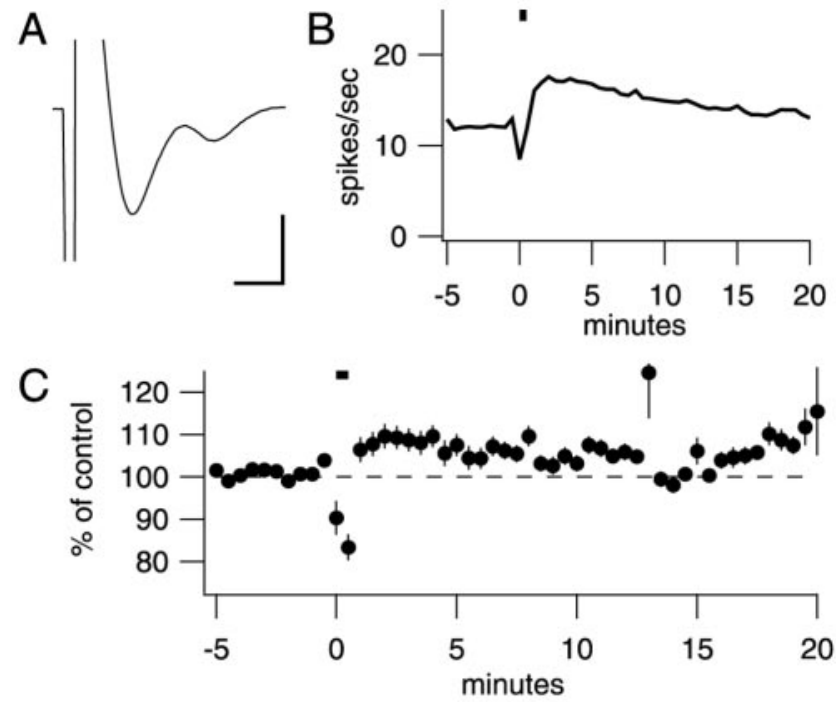

D

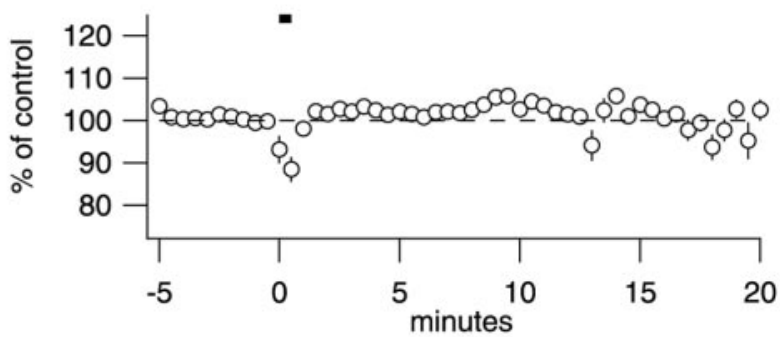

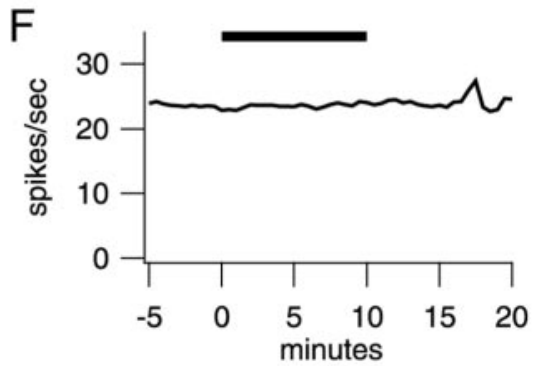

G

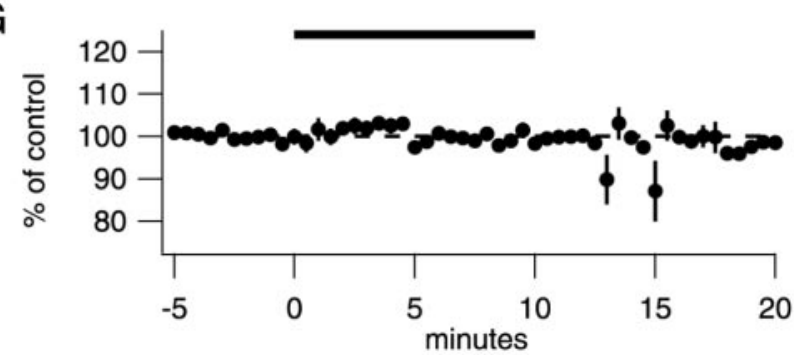

Figure 4. Stimulation of parallel fibers or basket cells to generate endogenous NO. A, To maximize NO production from PFs, presynaptic fiber volleys were measured and stimulus intensity was adjusted before each experiment. Average fiber volley across all experiments was $3.0 \pm 1.4 \mathrm{mV}$ (range, $2-5 \mathrm{mV}$ ). Calibration: $3 \mathrm{mV}, 0.5 \mathrm{msec}$. B, An example of one experiment. Five trains of stimuli ( $20 \mathrm{~Hz}$ for $5 \mathrm{sec}, 6 \mathrm{sec}$ intertrain interval) was delivered to the PFs at $t=0$ min. C, Average results from seven control cells; D, eight NOS inhibitor cells. NOS inhibitors block an increase in firing rate. At $t=20 \mathrm{~min}$, control cells tend toward higher firing rates, whereas cells in the presence of NOS inhibitors tend toward baseline firing rates. E, Paired recordings (1 whole-cell recording from a basket cell, 1 extracellular recording from a synaptically connected Purkinje neuron) were established in the absence of picrotoxin. Calibration: $20 \mathrm{mV}, 75 \mathrm{pA}, 100$ msec. F, After addition of $100 \mu \mathrm{m}$ picrotoxin to block the fast synaptic inhibition, a presynaptic basket cell was stimulated at time $t=0 \mathrm{~min}$. Little change in firing is visible in this example recording from the connected Purkinje neuron. $G, 0$ naverage, no significant increase could be detected in four pairs.
L-arginine to provide substrate for NOS, and transverse slices were used to preserve the PFs. In addition, blockers of glutamate [DNQX, 3-(2-carboxypiperazin-4-yl)propyl-1-phosphonic acid (CPP), and LY 367385] and $\mathrm{GABA}_{\mathrm{A}}$ (picrotoxin) receptors were present. Before each experiment, a presynaptic fiber volley was measured from the PFs in the dendritic arbor of the Purkinje neuron being recorded. Stimulus strength was adjusted so that the response size was between 2 and $5 \mathrm{mV}$; an example is shown in Figure 4A. Using these parameters, Shibuki and Kimura (1997) reported that single trains of stimuli $(5 \mathrm{sec}$ at $20 \mathrm{~Hz}$ ) evoked transient NO concentrations between 1 and $4 \mathrm{~nm}$ that lasted 10 sec. With the experimenter blinded to the condition, trains of presynaptic stimuli ( $20 \mathrm{~Hz}$ for $5 \mathrm{sec}$ repeated five times) were delivered to the PFs in either a control solution with the antagonists listed above or a solution to which an NOS inhibitor, either 7-nitroindazole $(10 \mu \mathrm{M})$ or $N$-nitro-L-arginine $(100 \mu \mathrm{M})$ had been added. Stimulation in control solution caused an immediate rise in firing rate in six of seven cells in the first 5 min after the stimulus (Fig. $4 C)(107.7 \pm 2.8 \% ; n=7$; significantly different from no change, $p=0.033$ ). With an NOS inhibitor present, this short-latency increase was not significant (Fig. 4D) (101.7 \pm $1.3 \% ; n=8 ; p=0.23)$. At $15-20$ min after stimulus, the control group but not the NOS inhibitor group remained significantly different from control [control, $106.4 \pm 2.4 \%, n=7, p=0.037$ (Fig. 4C); NOS inhibitors, $99.5 \pm 2.4 \%, n=8, p=0.84$ (Fig. 4D)].

We next tested whether basket cells could be stimulated to produce NO and cause increases in Purkinje neuron firing rates. A whole-cell recording was established from a basket cell, and an extracellular recording was used to identify a Purkinje neuron inhibited by that basket cell. An example of such a pair is shown in Figure 4E. After a connected pair had been identified in picrotoxin-free solution, $\mathrm{GABA}_{\mathrm{A}}$ receptors were blocked by adding picrotoxin to the bath. The basket cell was then prevented from firing by injection of hyperpolarizing current while a baseline firing rate was measured in the Purkinje neuron. After baseline data had been collected, the basket cell was made to fire bursts of action potentials by repeated depolarizing and hyperpolarizing current injections. Results from an example recording are shown in Figure $4 F$, and average results from four connected pairs are shown in Figure 4G. These manipulations had no significant effect on the firing rate of Purkinje neurons (Fig. $4 G$ ) $(101.2 \pm 1.8 \% ; n=4 ; p=0.55)$, and therefore the effects of NOS inhibitors were not tested.

\section{Discussion}

These experiments show that brief exposure to NO donors or cGMP can trigger long-lasting increases in the spontaneous firing rate of Purkinje neurons in the absence of fast synaptic inputs. Stimulation of PFs using a protocol known to release NO also caused increases in Purkinje neuron firing rates that were blocked by NOS inhibitors. Together, the data provide strong evidence that the observed effect is a result of NO stimulating sGC to generate an increase in cGMP concentration. cGMP could affect several different targets, including CNG channels, phosphodiesterases, or PKG (Hofmann et al., 2000). Experiments showed that a PKG inhibitor, KT5823, was able to block the NO-induced increase in firing rate, supporting a model in which modulation occurs through an NO-cGMP signaling cascade that involves sGC and PKG.

This modulation caused relative increases in firing rate up to $25 \%$. Although this may seem moderate, given baseline firing rates from 15 to $60 \mathrm{spikes} / \mathrm{sec}$, this represents $4-15$ extra spikes 
every second. Changes of this magnitude will most likely make a strong contribution to the output of the cerebellar cortex.

Previous work has suggested that NO modulates neural activity by changing excitatory synaptic strength. However, these studies indicating a role for NO in hippocampal long-term potentiation (Schuman and Madison, 1991, 1994; Zhuo et al., 1994a,b) and hippocampal long-term depression (LTD) (Son et al., 1998) remain controversial (Selig et al., 1996). Similarly, it has been suggested that NO is critically involved in cerebellar LTD (Hartell, 1994, 2001; Lev-Ram et al., 1995, 1997; Boxall and Garthwaite, 1996), although this remains in debate (Linden et al., 1995). The present study proposes an alternative role for NO in influencing neural activity.

To change the spontaneous firing rate of a neuron, ionic conductances in the cell membrane must be altered. At least two channels are attractive candidates: large-conductance, $\mathrm{Ca}^{2+}$ activated $\mathrm{K}^{+}$channels (BK) and the channels responsible for persistent or resurgent $\mathrm{Na}^{+}$current. In smooth muscle tissue, BK channels are facilitated by NO-cGMP (Archer et al., 1994). PKG has been reported to phosphorylate BK channels directly, and this modification shifts the voltage-activation curve to more hyperpolarized potentials (Alioua et al., 1998). Furthermore, it has been shown in pituitary nerve terminals that PKG activation increases channel open probability, and this modification seems to increase excitability, leading to more action potentials in response to current injection (Klyachko et al., 2001). Thus, in Purkinje neurons as in smooth muscle cells, PKG may facilitate a $\mathrm{K}^{+}$ conductance. However, unlike in muscle cells (but similar to pituitary terminals), this increase in potassium current may enhance the excitability of the Purkinje neuron by a mechanism by which the hyperpolarization facilitates a pacemaker current.

A second candidate conductance is a class of TTX-sensitive $\mathrm{Na}^{+}$currents that generates inward current flow between spikes (Uteshev et al., 1995; Bevan and Wilson, 1999; Raman and Bean, 1999). Recent evidence suggests that phosphorylation state tightly controls a resurgent $\mathrm{Na}^{+}$current in Purkinje neurons (Grieco et al., 2002). Our results imply that PKG may be responsible for maintaining the phosphorylation state of resurgent current. Interestingly, nitric oxide has been reported to facilitate a persistent $\mathrm{Na}^{+}$current in pituitary nerve terminals; however, this action is independent of cGMP-PKG (Ahern et al., 2000).

Our results suggest that integrated, local activity triggers longterm increases in Purkinje neuron excitability, but which afferents trigger NO production? We investigated two possible sources of endogenous NO production. Cerebellar granule cells and basket cells express NOS at high levels (Bredt et al., 1990). Direct electrical stimulation of PFs has been shown by Shibuki and Kimura (1997) to cause a $\mathrm{Ca}^{2+}$-dependent increase in NO concentration. Using the stimulus parameters from that study, we observed significant increases in firing rate that were blocked by NOS inhibitors. A complementary experiment on basket cells showed that high levels of activity in a single presynaptic basket cell could not cause an increase in the firing rate of a Purkinje neuron. Unfortunately, we were not able to test the effects of stimulating many basket cells simultaneously, and the possibility remains that such a concerted stimulus would also generate NOdependent changes in Purkinje neuron firing.

A major component of the output of cerebellar cortex consists of pauses in persistent firing of Purkinje neurons. These pauses facilitate firing of target premotor neurons in the cerebellar nuclei and vestibular nucleus (Eccles et al., 1967). By serving as a link between afferent activity and the intrinsic electrical activity underlying baseline firing of Purkinje neurons, this new mechanism could help to maintain Purkinje neuron output within a proper dynamic range. In this way, afferent-induced, long-term increases in baseline firing rate of Purkinje neurons might allow for a wider range of disinhibitory signals to be transmitted from the cerebellar cortex to its targets.

Given that NO-cGMP elements are expressed throughout the brain, this mechanism may be widespread, producing activitydependent, persistent adjustments in the baseline firing rate of endogenously active neurons.

\section{References}

Ahern GP, Hsu SF, Klyachko VA, Jackson MB (2000) Induction of persistent sodium current by exogenous and endogenous nitric oxide. J Biol Chem 275:28810-28815.

Alioua A, Tanaka Y, Wallner M, Hofmann F, Ruth P, Meera P, Toro L (1998) The large conductance, voltage-dependent, and calcium-sensitive $\mathrm{K}^{+}$ channel, Hslo, is a target of cGMP-dependent protein kinase phosphorylation in vivo. J Biol Chem 273:32950-32956.

Archer SL, Huang JM, Hampl V, Nelson DP, Shultz PJ, Weir EK (1994) Nitric oxide and cGMP cause vasorelaxation by activation of a charybdotoxin-sensitive K channel by cGMP-dependent protein kinase. Proc Natl Acad Sci USA 91:7583-7587.

Ariano MA, Lewicki JA, Brandwein HJ, Murad F (1982) Immunohistochemical localization of guanylate cyclase within neurons of rat brain. Proc Natl Acad Sci USA 79:1316-1320.

Armstrong DM, Rawson JA (1979) Activity patterns of cerebellar cortical neurones and climbing fibre afferents in the awake cat. J Physiol (Lond) 289:425-448.

Bevan MD, Wilson CJ (1999) Mechanisms underlying spontaneous oscillation and rhythmic firing in rat subthalamic neurons. J Neurosci 19:7617-7628.

Boxall AR, Garthwaite J (1996) Long-term depression in rat cerebellum requires both NO synthase and NO-sensitive guanylyl cyclase. Eur J Neurosci 8:2209-2212.

Brasnjo G, Otis TS (2001) Neuronal glutamate transporters control activation of postsynaptic metabotropic glutamate receptors and influence cerebellar long-term depression. Neuron 31:607-616.

Bredt DS, Hwang PM, Snyder SH (1990) Localization of nitric oxide synthase indicating a neural role for nitric oxide. Nature 347:768-770.

du Lac S, Lisberger SG (1995) Membrane and firing properties of avian medial vestibular nucleus neurons in vitro. J Comp Physiol [A] 176:641651.

Eccles JC, Ito M, Szentagothai J (1967) The cerebellum as a neuronal machine. New York: Springer.

Ghamari-Langroudi M, Bourque CW (2000) Excitatory role of the hyperpolarization-activated inward current in phasic and tonic firing of rat supraoptic neurons. J Neurosci 20:4855-4863.

Grieco TM, Afshari FS, Raman IM (2002) A role for phosphorylation in the maintenance of resurgent sodium current in cerebellar Purkinje neurons. J Neurosci 22:3100-3107.

Hartell NA (1994) cGMP acts within cerebellar Purkinje cells to produce long term depression via mechanisms involving PKC and PKG. NeuroReport 5:833-836.

Hartell NA (2001) Receptors, second messengers and protein kinases required for heterosynaptic cerebellar long-term depression. Neuropharmacology 40:148-161.

Häusser M, Clark BA (1997) Tonic synaptic inhibition modulates neuronal output pattern and spatiotemporal synaptic integration. Neuron 19:665-678.

Hofmann F, Ammendola A, Schlossmann J (2000) Rising behind NO: cGMP-dependent protein kinases. J Cell Sci 113:1671-1676.

Kimura S, Uchiyama S, Takahashi HE, Shibuki K (1998) cAMP-dependent long-term potentiation of nitric oxide release from cerebellar parallel fibers in rats. J Neurosci 18:8551-8558.

Klyachko VA, Ahern GP, Jackson MB (2001) cGMP-mediated facilitation in nerve terminals by enhancement of the spike afterhyperpolarization. Neuron 31:1015-1025. 
Lev-Ram V, Makings LR, Keitz PF, Kao JP, Tsien RY (1995) Long-term depression in cerebellar Purkinje neurons results from coincidence of nitric oxide and depolarization-induced $\mathrm{Ca}^{2+}$ transients. Neuron 15:407-415.

Lev-Ram V, Nebyelul Z, Ellisman MH, Huang PL, Tsien RY (1997) Absence of cerebellar long-term depression in mice lacking neuronal nitric oxide synthase. Learn Mem 4:169-177.

Linden DJ, Dawson TM, Dawson VL (1995) An evaluation of the nitric oxide/cGMP/cGMP-dependent protein kinase cascade in the induction of cerebellar long-term depression in culture. J Neurosci 15:5098-5105.

Llinas R, Sugimori M (1980) Electrophysiological properties of in vitro Purkinje cell somata in mammalian cerebellar slices. J Physiol (Lond) 305:171-195.

Lohmann SM, Walter U, Miller PE, Greengard P, De Camilli P (1981) Immunohistochemical localization of cyclic GMP-dependent protein kinase in mammalian brain. Proc Natl Acad Sci USA 78:653-657.

Raman IM, Bean BP (1997) Resurgent sodium current and action potential formation in dissociated cerebellar Purkinje neurons. J Neurosci 17:4517-4526.

Raman IM, Bean BP (1999) Ionic currents underlying spontaneous action potentials in isolated cerebellar Purkinje neurons. J Neurosci 19:1663-1674.

Raman IM, Gustafson AE, Padgett D (2000) Ionic currents and spontaneous firing in neurons isolated from the cerebellar nuclei. J Neurosci 20:9004-9016.

Schlichter DJ, Casnellie JE, Greengard P (1978) An endogenous substrate for cGMP-dependent protein kinase in mammalian cerebellum. Nature 273:61-62.

Schlichter DJ, Detre JA, Aswad DW, Chehrazi B, Greengard P (1980) Localization of cyclic GMP-dependent protein kinase and substrate in mammalian cerebellum. Proc Natl Acad Sci USA 77:5537-5541.

Schuman EM, Madison DV (1991) A requirement for the intercellular messenger nitric oxide in long-term potentiation. Science 254:1503-1506.

Schuman EM, Madison DV (1994) Locally distributed synaptic potentiation in the hippocampus. Science 263:532-536.

Selig DK, Segal MR, Liao D, Malenka RC, Malinow R, Nicoll RA, Lisman JE (1996) Examination of the role of cGMP in long-term potentiation in the CA1 region of the hippocampus. Learn Mem 3:42-48.

Shibuki K, Kimura S (1997) Dynamic properties of nitric oxide release from parallel fibres in rat cerebellar slices. J Physiol (Lond) 498:443-452.

Son H, Lu YF, Zhuo M, Arancio O, Kandel ER, Hawkins RD (1998) The specific role of cGMP in hippocampal LTP. Learn Mem 5:231-245.

Uteshev V, Stevens DR, Haas HL (1995) A persistent sodium current in acutely isolated histaminergic neurons from rat hypothalamus. Neuroscience 66:143-149.

Zhuo M, Kandel ER, Hawkins RD (1994a) Nitric oxide and cGMP can produce either synaptic depression or potentiation depending on the frequency of presynaptic stimulation in the hippocampus. NeuroReport 5:1033-1036.

Zhuo M, Hu Y, Schultz C, Kandel ER, Hawkins RD (1994b) Role of guanylyl cyclase and cGMP-dependent protein kinase in long-term potentiation. Nature 368:635-639. 